\title{
THE LOCATIVE-APPLICATIVE IN ELEME ${ }^{1}$
}

\author{
By Oliver BOND \\ School of Oriental and African Studies
}

\begin{abstract}
The Eleme locative-applicative $=r \tilde{u}$ is a non-canonical applicative that demonstrates morphosyntactic properties commonly associated with clitics. It is employed in one of two functions: (i) to indicate an increase in the transitivity of a clause and (typically) to introduce an otherwise oblique function as a core argument of a base verb, or (ii) to indicate the presence of an atypical verbal complement. It is usually found in constructions containing a verb stem that expresses location, directed motion or transfer, but also functions as an obligatory component of the Eleme progressive construction. While locative and comitative expressions are common source-constructions for progressives in Niger-Congo languages, Eleme is apparently unique within the literature in that it includes an applicative with comitative function that must be enclitic to a verb of location to express progressive aspect.
\end{abstract}

\section{INTRODUCTION}

Applicatives are a characteristic feature of Benue-Congo languages including Eleme, an Ogonoid (Cross River, Benue-Congo, Niger-Congo) language of southeastern Nigeria. In this paper, it is argued that the Eleme clitic $=r \tilde{u}$ is a noncanonical applicative that either changes the valence of a base verb to allow the expression of an additional core argument or is used to signal the presence of a complement that is semantically and morphosyntactically atypical for the verb to which it is enclitic. In particular, one of the functions of $=r \tilde{u}$ is to introduce a 
range of locative complements for verbs that usually express directed motion; it also introduces comitative complements where the verb is one that usually has a locative complement. The requirement for the presence of such morphology appears to be related to both the argument structure of the base verb and semantic restrictions on the complements typically selected by those verbs. Given these qualities, I demonstrate that contrary to the popular view that applicatives are affixes that introduce an otherwise peripheral adjunct as a core object argument, in some instances they can be used to introduce an element that is neither a core argument nor a typical complement.

Section 2 outlines the clearest examples of the applicative function of $=r \tilde{u}$ with verbs of location and directed movement, where it is shown to introduce an animate participant as a core argument. Through examining both the usage and restrictions on the occurrence of $=r \tilde{u}$, it is demonstrated that this formative is also a necessary component in the Eleme progressive construction. In such constructions, the applicative introduces a nominalised event as a complement of a location verb. It is shown that event nominals encoded morphologically as dependent verb stems are licensed in a similar way to core functions rather than unmarked locative complements, or obliquely encoded locatives. Section 3 focuses on the clitic-like properties of $=r \tilde{u}$ which make it unlike prototypical derivational morphemes in terms of its variable position within the clause. Through discussing the semantic and structural contrasts between oblique functions and applicative objects in relation to a verb of transfer, I demonstrate the differences between the locative-applicative and regular prepositions in Eleme. In this section it is shown that the locative-applicative introduces inanimate objects in addition to animate objects and nominalised event complements. Thereafter I provide evidence for why analysing $=r \tilde{u}$ as a non-canonical applicative is more appealing than some other possible treatments. A summary is provided in section 4, where I conclude that $=r \tilde{u}$ licenses verbal complements that are atypical 
when compared to those usually permitted by the base verb with which it is associated. $^{2}$

\section{THE APPLICATIVE FUNCTION OF $=r \tilde{u}$}

Applicatives are the morphological instantiation of a special licensing relationship between a verb and its object argument(s). Constructions comprising applicatives are defined by Peterson (2007: 1) as 'a means some languages have for structuring clauses which allow the coding of a thematically peripheral argument or adjunct as a core-object argument.' As such, the types of argument licensed by an applicative bear a subset of thematic roles that might otherwise be encoded obliquely (rather than like core-functions), such as beneficiaries, instruments and concomitants.

Applicatives are usually considered to belong to a typological class of elements termed 'valence-changing morphology'. Changes in valence concern adjustments in the number and/or arrangement of syntactic arguments present in any given clause. In this sense, such valence-changing operations have both a syntactic and a semantic dimension. The use of an applicative does not always signal a change in the number of core arguments a verb has (cf. Harford 1993, Mabugu 2002, 2004, Marten 2002, 2003, Rapold 1997), but for the term to be used in a standard manner, changes to the argument frame of the verb with which it is associated must be at least one of its grammatical functions.

Changes in grammatical valence are the manifestation of differences in transitivity. This term is frequently used in the literature in relation to the properties of both verbs and clauses to account for the relationship between a verb and its arguments. Verbs described as transitive are characterised by the ability to take A and P arguments, the 'agent-like' and 'patient-like' arguments of a canonical transitive clause (in the sense of Comrie 1978). Intransitive verbs do not exhibit this ability and so only have an S argument: the single argument of a 
canonical intransitive clause. In a typical characterisation of valence-increasing morphology, the use of an applicative with an intransitive verbal base will derive a transitive clause, while the use of an applicative with a transitive base will derive a ditransitive clause with two object arguments. In ditransitive clauses one of the objects is referred to as the T argument (mnemonic for 'theme') and the other as either the G argument (mnemonic for 'goal'), as in Croft (2003) or the R argument (mnemonic for 'recipient') as favoured by Siewierska (2004) and Margetts \& Austin (2007). Which label is most appropriate for each object is determined by its thematic role. Likewise, it is common to distinguish between the base object - the one associated with the basic (underived) verb root, and the applicative object (sometimes also called the applied object) - the one associated with the applicative marker (Peterson 2007: 7).

Grammatical valence can be distinguished from semantic valence, which concerns the number of participants that are implicit in the scene expressed by the verb. The number of arguments (or grammatical relations) in a clause, therefore, does not necessarily reflect the number of participants implicit in the scene. Prototypical participants play central roles in the event depicted. In contrast, circumstantial roles (such as benefactives, i.e. a non-participatory entity, or circumstantial comitatives) form part of the setting for an event (Andrews 2007: 140). It is exactly these peripheral roles that applicatives are typically used to introduce as applicative objects. In the following three sections I briefly introduce two uncontroversial applicatives in Eleme (section 2.1), before discussing differences between the use of the locative-applicative with directed motion verbs (section 2.2) and location verbs (section 2.3).

\subsection{Applicatives in Eleme}

Eleme has three applicative morphemes: the benefactive suffix $-s \varepsilon$, the instrumental suffix $-m a$ and the locative-applicative clitic $=r \tilde{u}$. Each of these 
morphemes may be used to introduce an applicative object argument to a clause. Grammatical relations in Eleme exhibit the morphosyntactic properties of a nominative/accusative system and objects are thus encoded distinctly from transitive (A) and intransitive (S) subjects. These core functions are differentiated through word order and indexation of both subject and object arguments on verbal elements. There is no case marking in the language. The basic word order is SVO, both in main clauses and subordinate clauses. Cross-referencing of arguments is common; typically some or all arguments are indexed through affixation (see Bond 2006a for details of the highly complex system of verbal agreement). Subjects in Eleme are the controllers of at least four different agreement paradigms, including both verbal prefixes and suffixes. There are also two paradigms of pronominal suffixes indexing animate objects, with some variability in the marking of inanimate objects, which tend to be unmarked. ${ }^{3}$ Eleme appears to lack a productive passive construction, but syntactic evidence for the distinction between animate subjects and objects is provided from the logophoric reference system (Bond 2006b). Oblique functions (i.e. circumstantial roles) are typically introduced by a range of prepositions; the most general of which, oso 'in/into/at', is undoubtedly also the most frequent. ${ }^{4}$ Oblique functions in Eleme are generally locative in nature.

Inherently ditransitive verbs are rare in Eleme and three-participant events are usually encoded in serial-verb constructions or through the use of one of the three applicative suffixes identified above. The benefactive suffix increases the valence of the verb in order to overtly express the beneficiary of the situation described by the verbal predicate. In (1a) the base verb $d_{3} a ́$ has pronominal subject (or A) àbà with which it agrees in person and number, and a single NP object (or P) j̀lùd $z a$ 'orange'. In (1b) the benefactive suffix -se licenses an additional core argument, as indicated by the third-person singular object suffix $-y e$. In this example j̀lùd $z a$ 'orange' is the base object and the beneficiary is the applicative object (i.e. the recipient-like $\mathrm{R}$ argument introduced by the benefactive suffix). The benefactive 
suffix occurs closer to the verb root than subject and object suffixes, when they are present. ${ }^{5}$
a. àbà dzá-ri òlũ̀dza
3PL buy-3PL orange

'They bought an orange.'

\section{b. àbà dzá-se-ri-ye j̀lù̀dza \\ 3PL buy-BEN-3PL-O3SG orange}

'They bought an orange for him.'

An alternative, and far more productive construction for expressing a beneficiary involves the use of a serial-verb construction, whereby the second transitive verb $n \varepsilon$ 'give' introduces the beneficiary, as in (2):

$$
\begin{aligned}
& \text { àbà dzá-ri j̀lừdza ne òsáro } \\
& \text { 3PL buy-3PL orange give Osaro }
\end{aligned}
$$

'They bought an orange for Osaro.'

In addition to a benefactive suffix, Eleme also has an instrumental suffix - $m a$. The instrumental indicates that an object instrument is used to carry out the event expressed by the verb stem to which it is attached. For instance, in (3a) àkpá-rã 'my bag' is the base object of the transitive verb bo' 'tie', while the subject NP is

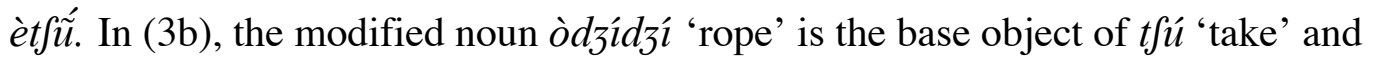
the morphologically unexpressed applicative object of bó 'tie' in the following clause. The use of the instrumental suffix indicates that the rope is used to tie up the animate patient of bó 'tie', expressed by the third-person-singular default object suffix $-a$. In (3b), as in (1b), the object suffix follows the applicative. 
(3)

a. èt $\int \tilde{u} \quad$ bó àkpá-rã

cloth tie bag-1SG.POSS

'Cloth ties my bag (to something).'

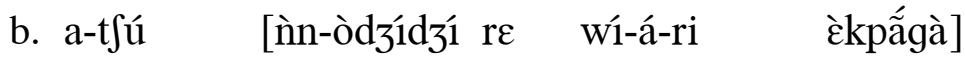

3.AP-take one-rope REL call-HAB-3PL ekpanga

a-bó-ma-a

3.AP-tie-INS-O3SG

'She took the rope that they call ekpanga and she tied him with (it).'

The instrumental $m a$ - is itself a non-canonical applicative in that it does not clearly license a new syntactic argument of its verb but rather indicates that an argument of another verb is also interpreted as an instrumental verb of the marked verb.

Of the applicative morphemes identifiable in Eleme the most noteworthy is the locative-applicative $=r \tilde{u}$, which is typically found in constructions containing a verb stem that expresses location, directed motion or transfer. This applicative marker either increases grammatical valence by licensing an additional core object argument or signals the presence of a semantically atypical complement for that verb. Although usually attached to a verb stem, it has properties that make it unlike a typical verbal affix and as such its distribution contrasts with the other applicatives in the language. A detailed look at its morphosyntactic distribution is provided in section 3 .

\subsection{The locative-applicative with directed motion verbs}

In order to illustrate the distribution of the locative-applicative, compare the following examples which each include the verb ?à 'leave'. 
(4)

\author{
a. òsáro ?à \\ Osaro leave
}

'Osaro left.' b. òsáro ià ìtfíá

Osaro leave Nchia

'Osaro left Nchia [PLACE].'

Example (4a) contains an intransitive clause that semantically specifies movement of the agent, Osaro, away from a location. The location from where the referent of the subject began his journey is not explicit in this construction; the original spatial location of the protagonist is available either in the discourse context of the utterance or available form shared knowledge. In Talmy's $(2000,2007)$ Figure and Ground framework for describing cognitive anchors, a basic Motion event like in (4) consists of one object, known as the FIGURE, moving or being located in respect to another object, i.e. a reference object referred to as the GROUND. ${ }^{6}$ His framework provides a useful way of discussing the contrasts evident between the examples with and without the locative-applicative. In (4), Osaro is the Figure and the lexical verb encodes information about MOTION and the PATH of that motion away from the deictic centre (i.e. the Ground). In (4a) Figure, Motion and Path are overtly encoded and the Ground is not. However, the same verb stem may also be accompanied by a locative object, as in (4b). With ?à 'leave' the semantic role of the locative object is a SOURCE. ${ }^{7}$ Specific, definite locations of this kind are the morphologically unmarked locative complement of a directed motion verb. The examples in (5) differ from those in (4) in that an animate participant is expressed as the Ground element of the motion event.

$$
\begin{array}{rlr}
\text { a. òsáro } & \text { ?à=rú́ } & \text { òsíla } \\
\text { Osaro } & \text { leave=APPL } & \text { Osila }
\end{array}
$$

'Osaro left Osila [PERSON].' 
b. òsáro Pà=rû́ òsíla ala ǹt fiá

Osaro leave=APPL Osila at Nchia

'Osaro left Osila in Nchia.'

In (5a) the lexical verb is marked by the locative-applicative, allowing the expression of an animate participant as the Ground of the Motion event. The location of Osila is identical to the source location of the agent, making Osila the THEME or PROTO-PATIENT (in the sense of Dowty 1991) but also an indirect reference to the source location of the movement. In this example Osila is the applicative object of the verb. In (5b), where the location of the event is overtly expressed, the location, Nchia, is introduced by a preposition ala 'in/at' as an optional oblique phrase. The examples in (4) and (5) differ in that the P argument, Osila, is obligatory in (5), while the location in (4) is optional.

Obliquely encoded locatives such as the PP ala ìtfía in (5b) specify the location of the event or state as a whole. For ǹtflá to be used in this context it requires overt structural coding in the form of the preposition. Notably, this preposition does not encode information about the Path of the motion. Locative expressions of this kind contrast with locatives which are not morphologically marked when they occur with a verb of motion or static location. Such is the case with verbs like $? \grave{a}$ 'leave (a place)' and $g^{w} \tilde{\tilde{a}}$ 'reach (a place)' which are characterised by motion away from a specific source location and towards a specific destination respectively. In each case, only one location is central to the meaning of the predicate. Such locatives do not require overt structural coding in order to occur with verbs of this type, demonstrating that they are the morphologically unmarked type of complement; they equate with the Ground in Talmy's framework of Motion events. The third and final type of locative distinguished here are 'participant' locatives whereby an animate or inanimate participant is equated semantically with a location and as such an entity is taken to equate to the Ground. Morphosyntactically, 'participant' locatives are treated like 
other core functions (i.e. have argument status) in Eleme, in fact the treatment of locatives as core participants is rather widespread in Africa (cf. Dimmendaal 2003). The participant introduced by $=r \tilde{u}$ is clearly an argument since, if animate, it may not be omitted unless replaced by a bound object pronoun, as in (6), where in each example the argument licensed by the applicative is encoded by an object suffix. This is not the case in (4a) where the lack of an overt location NP does not entail or allow the presence of an object suffix.
a. òsáro Pà-a=rú́
b. Pá-mu=rú
Osaro leave $\mathbf{- O 3 S G = A P P L}$
'Osaro left her.'
leave. $\mathrm{IMP}-\mathbf{O} 1 \mathrm{SG}=\mathrm{APPL}$
'Leave me alone!'

With this argumentation in mind it is possible to account for why constructions such as those in (7) are not permissible: in (7a) Osila is not an unmarked locative expression and so cannot occur without some form of structural coding; in (7b) Nchia is not a 'participant' locative (and therefore not a verbal argument); and in (7c) the NP indicating the additional participant introduced by the locativeapplicative is missing:
a. *òsáro ?à òsíla
b. *òsáro Pà=rú́
ǹt
Osaro leave Osila
Osaro leave $=\mathrm{APPL}$ Nchia
Intended: 'Osaro left Osila.'
Intended: 'Osaro left Nchia.'
c. *òsáro Rà=rú́
Osaro leave $=\mathrm{APPL}$

Intended: 'Osaro left her.'

These examples demonstrate that in Eleme genuine spatial locations (which are either morphologically unmarked or obliquely encoded with a preposition) are 
encoded differently from 'participant' locatives, which require the use of the locative-applicative to be expressed as a verbal complement. One possible functional label for the use of the locative-applicative here is DISASSOCIATIVE since in these examples the agent is disassociated from the patient, as is clear from the imperative example in (6b) (cf. the use of the term ASSOCIATIVE as an alternative to the term COMITATIVE). ${ }^{8}$ They also illustrate that the $=r \tilde{u}$ morpheme introduces an animate participant as a core argument of the verb, thereby rearranging the argument frame of the verb as well as increasing the transitivity. For the verb $? \grave{a}$ 'leave', spatial locations are distinct from animate participants in that only the latter are structurally coded by the locative-applicative. In terms of transitivity, the difference between these sets of examples is reflected in the number of participants in the scene expressed by the clause. The parameters associated with high individuation of a participant identified by Hopper \& Thompson (1980) certainly distinguish animate participants from locations. For the time being, it is possible to express differences in the use of $=r \tilde{u}$ based on the observation that 'participant' locatives that require $=r u \tilde{u}$ have core-like functions, while spatial locatives do not.

When a motion verb has a path determined in relation to a deictic centre like ?à 'leave', the locative-applicative is used when the deictic centre is not an inherently static location but rather a non-canonical locative, in this case a human animate. Some other verbs of motion in Eleme behave in a similar way to ?à 'leave' in this respect. One such example, $g^{w} \dot{\tilde{a}}$ 'reach', is used here to exemplify other more complex uses of the locative-applicative. In (8), $g^{w} \grave{\tilde{a}}$ 'reach' is found both with and without the applicative marker: 


$$
a-g^{w} \text { à } \quad\left[\text { ǹté } \quad k e \quad \text { è-g } g^{w} \text { à=rú } \quad \text { até }\right]
$$

\section{AP-reach when PRTCL 3-reach=APPL father}

'The time came when he reached his father.'

In the first case, $g^{w} \grave{\tilde{a}}$ does not appear with the applicative and is followed by a locational phrase that expresses a point in time (enclosed in brackets). Conversely, the second instance of $g^{w} \overline{\tilde{a}}$, which forms part of the location required by the first verb, is accompanied by the locative-applicative. In this case, the verb form is followed by an argument comprising an animate participant, that is, a 'participant' locative.

In addition to taking a phrase that specifies a location in time, $g^{w} \grave{\tilde{a}}$ may also be accompanied by a location in space. The examples in (9) illustrate a range of different alternatives in this respect. The first construction in (9a) contains a demonstrative expressing a definite location. The second example in (9b) features

$g^{w} \tilde{\tilde{a}}$ followed by a preposition delimiting the direction of movement and a location. Note, however, that a third option is also available in the language, as exemplified in (9c). Here the preposition implies the location that is reached based on information elsewhere in the construction (i.e. under the house).
a. a-1à
Sí $\quad \mathrm{a}-\mathrm{g}$ wà
วิวั̀mว́ni

3.AP-leave go 3.AP-reach there

'He left and reached the place.'

b. a-Pà-ri

si $g^{\mathrm{w}}$ ã̀ $\quad$ oso è?ó

3.AP-leave-3PL go reach in bush

'They left to go into the bush.' 


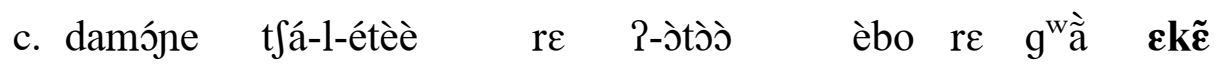
all.people run-each-race REL leave-house top REL reach under 'All the people ran from the upstairs to the downstairs.'

To summarise, the examples given in (8) and (9) indicate that the meaning of constructions containing $g^{w} \tilde{a}$ 'reach' without the use of the applicative may be more specifically characterised as having the meaning 'reach a location or point in time'. Conversely, in constructions containing both $g^{w} \grave{a}$ and the applicative marker, a nominal is introduced as a core argument of the verb. The semantic distinction between the two types of complement is indicated by the choice of question word in content questions such as those in (10):
a. òsáro g gã̀ modé
b. òsáro $\mathrm{g}^{\mathrm{w} \text { à̀}=r u ̂ ́ ~} \quad$ àm $\varepsilon$
Osaro reach where
Osaro reach $=\mathbf{A P P L}$ who
'Where did Osaro reach?'
'Who did Osaro reach?'

Furthermore, as with the constructions with $\stackrel{x}{a}$ 'leave' discussed above, the constructions in (11) show that animate objects can be indicated by an independent NP or an object suffix attached to the verb stem.

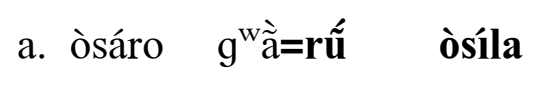
b. òsáro $g^{\mathrm{w}}$ ã̀-ã $=r$ ú
Osaro reach $=\mathrm{APPL}$ Osila
Osaro reach $\mathbf{- 3} \mathbf{S G}=\mathbf{A P P L}$
'Osaro reached Osila.'
'Osaro reached her.'

So far, the examples presented containing $2 \grave{a}$ 'leave' and $g^{w} \grave{a}$ 'reach' with the locative-applicative have all included an animate participant. However, $=r \tilde{u}$ may also be used to introduce inanimate participants (see section 3.1 for examples) or dependent verb forms which take the place of a more typical complement. 
Dependent verb forms in Eleme are characterised by distinct morphological and distributional properties. The term is used to refer to an element that comprises a lexical root that is morphologically unmarked when employed in predication of actions, and encoded with additional morphology when used in reference to an action. These nominalised verbs are characterised by the dependent prefix $e-/ \mathcal{E}$ which is derivational in nature and undergoes vowel harmony with the stem to which it attaches. Monosyllabic roots also usually exhibit a dependent suffix $-\varepsilon /-a /-\tilde{a}$, although it is frequently absent. Disyllabic roots only ever take a dependent prefix and never a suffix. In terms of their syntax, dependent verb forms do not exhibit the range of uses regular nominals do; for instance, they cannot be used as subjects. They are always found in the position following the verb to which they are the complement and exhibit a dependency relationship with the head of the predicate which must be a lexical verb. Dependent verb forms are best classified as non-finite in nature, but do inflect for subject agreement morphology under certain conditions (see Bond 2006a for details). Other productive nominal morphology is not apparent in Eleme and therefore cannot contribute to the overall characterisation of dependent verbs as 'nominalised'. In (12), the presence of the dependent verb form is marked in the clause in the same way that a 'participant' locative would be, i.e. using $=r \tilde{u}$.

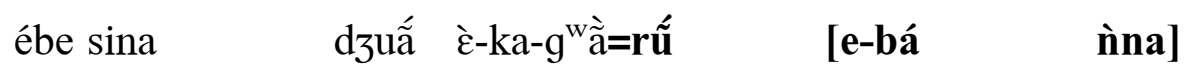

$$
\begin{aligned}
& \text { as catch.animal bring 3-CONT-reach=APPL DEP-eat.flesh meat } \\
& \text { ka-ra-gbó ǹ̀gbau lò ekpã́ ǹsã́ } \\
& \text { CONT-3PL-drive dog remove near fire }
\end{aligned}
$$

'Although he [the dog] caught animals, when it comes to the [act of] eating meat, they will drive the dog away from the fire.'

In this example the dependent verb form does not represent a time, but rather refers to the act of eating meat, and I assume the event indicated by the dependent 
verb is construed as a type of location by metaphorical extension. However, this does not account for the use of the locative-applicative in this construction. Furthermore, nominalised events do not exhibit the type of behaviour expected of genuine NP arguments, for instance, they are never the subjects of verbs and cannot be replaced by an object pronoun or be omitted altogether. Through comparison of these examples with ones containing verbs of location (section 2.3) and transfer (section 3.1), I propose that what underlies the use of $=r \tilde{u}$ here is the fact that the complement of the verb in each case is semantically atypical for that verb, in that either a 'participant' locative or nominalised event is construed as the Ground in a Motion event rather than a spatial or temporal location (which would remain unmarked in this respect).

\subsection{The locative-applicative with location verbs}

Verbs of location behave like directed motion verbs in terms of the circumstances in which they occur with $=r \tilde{u}$, yet in such constructions they have a comitative function rather than a locative or disassociative one. In prototypical locative predicates $d o$ 'be located/exist' is obligatorily followed by a location, as in (13a). In existential constructions the locative verb is followed by an obligatory particle

?ấ, glossed as EXST, as in (13b). The exact meaning of this particle is unclear, and it is perhaps restricted to only this context.

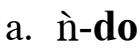
ekpã́ ǹsã́
b. ǹsã do
ใắ
1SG-be.located near fire
book be.located EXST
'I am near the fire.'
'There's a book.'

The locative verb is also used in the predication of adjectives but not in nominal predications, which require the use of a dedicated copula with restricted 
inflectional potential. While the locative verb is inflected with agreement suffixes if the subject is second-person or third-person plural, as in (14a), the copula is not, as in (14b). In terms of person and number marking, the locative verb do exhibits the default personal inflection pattern associated with verbal constructions in Eleme and can be reduplicated to indicate persistence, as with other verbs. However, it is nevertheless a defective verb in the sense that it is limited to inflection with the default subject-marking affixes only, contra more prototypical verbs, and cannot occur with affixes marking aspect (Bond 2006a). ${ }^{9}$
a. àbà do-ri
àka
b. àbà be òkũséwíne
3PL be.located-3PL good
3PL COP children

'They are good.'

'They are children.'

When $d o$ occurs with $=r \tilde{u}$ it functions as a comitative, and may be used to introduce an additional animate participant, as in (15b). A similar situation holds for the use of $=r \tilde{u}$ with $t \tilde{\partial}$ 'stay, live', in which case the interpretation is 'lived with', as in (16b). Talmy (2007: 70) treats events of static location like events involving movement and thus in each of the examples below, Osaro is the Figure and the Ground is either Ebubu, as in (15a) and (16a), or Osila, as in (15b) and (16b):
a. òsáro do
èbubu
b. òsáro do=rú
òsíla
Osaro be.located Ebubu
'Osaro is in Ebubu.'
Osaro be.located=APPL Osila
'Osaro is with Osila.'

a. òsáro t̃̃ èbubu

Osaro stay Ebubu

'Osaro lived in Ebubu.' b. òsáro tõ=rú òsíla

Osaro stay=APPL Osila

'Osaro lived with Osila.' 
These examples are interesting because they demonstrate how the meaning of $=r \tilde{u}$ is largely dependent on the semantic characteristics of the verb to which it attaches. In particular, the disassociative meaning that arises when the locativeapplicative is used with ?à 'leave' semantically opposes the comitative meaning that prevails with verbs of location. It is for this reason that the label 'locativeapplicative' is adopted as a neutral term here, rather than, for instance, 'comitative'.

Like $g^{w} \tilde{\tilde{a}}$ 'reach', $d o$ 'be located/exist' and $t \tilde{\supset}$ 'stay, live' may also occur with the locative-applicative and a dependent verb form. In such cases, the construction has a progressive reading, as exemplified in (17):

$$
\begin{aligned}
& \text { ǹ-do=rú } \quad \text { e-tere ǹdzirá } \\
& \text { 1SG-be.located=APPL DEP-cook fish } \\
& \text { 'I am in the process of cooking fish.' }
\end{aligned}
$$

Cross-linguistically, progressive aspect is used in discourse when a speaker views a situation as ongoing at a reference time. Situations encoded with progressive aspect are prototypically dynamic: Dahl (1985: 91) defines progressive aspect in terms of a relation between a dynamic situation and a point in time. Dynamic situations involve change or movement (Comrie 1976: 48-50, Dahl 1985: 28) and typically have internal structure. They contrast with states, which are prototypically extended, less transitory, persistent situations characterised by a homogenous structure in which successive intervals do not differ (cf. Frawley 1992: 146-8, Timberlake 2007: 284).

Despite their dynamic interpretation, constructions encoding progressive aspect exhibit a strong tendency to derive from expressions involving locative elements such as postural verbs ('sit', 'stand', 'lie') or more general locative verbs without reference to a specific posture ('be at', 'stay', 'live'), such as $d o$ 'be located/exist' and $t \tilde{\partial}$ 'stay, live' in Eleme. The prevalence of progressive 
constructions with a locative origin is particularly notable in African languages (Heine \& Kuteva 2002). In fact Bybee, Perkins \& Pagliuca (1994: 129-33) suggest that all progressives may ultimately derive from 'grams' (grammatical morphemes) with some form of locative meaning. Progressive constructions of this kind are proposed to develop diachronically from a locative source construction in which the form denoting the activity in progress is - by way of spatial metaphor - treated in a similar way to a location (Heine, Claudi \& Hünnemeyer 1991, Bybee, Perkins \& Pagliuca 1994).

While the Eleme progressive construction comprises the semantic and grammatical components anticipated for a prototypical expression of progressive aspect, it differs from the progressive commonly exemplified in the literature in that it obligatorily includes a valence-changing clitic, namely the applicative $=r \tilde{u} .{ }^{10}$ While periphrastic progressives of this kind frequently involve locative verbs and non-finite verb forms, valence-changing morphology is seldom, if ever mentioned as a component (see for instance the forms listed in Bybee, Perkins \& Pagliuca 1994: 128-9 and Dahl 1985: 90-1). However, comitatives have been argued by Heine \& Kuteva (2002: 83) to be part of an alternative diachronic source construction for progressives in branches of the Niger-Congo family, including the Adamawa-Ubangi languages Baka and Ngbaka Ma'Bo, and the Bantu languages Swahili and Umbundu (which, like Eleme, are Benue-Congo languages). ${ }^{11}$ Given that the comitative function is one of the uses of the locativeapplicative in Eleme, it seems reasonable to draw analogies between these structures. In those cases where a comitative is an obligatory part of the progressive, it does not appear to be the case that a verb of location or a stative auxiliary is also required as the head of the predicate. In fact, with the possible exception of Umbundu progressive construction, which is characterised by the presence of a copula (Valente 1964: 281, Schadenberg 1990: 49), the Eleme progressive construction seems unique in its structure when compared to other comitative-type progressives mentioned in the grammaticalization literature. While it is acknowledged that it is common for progressives to be based on locative or comitative expressions and a nominalised or infinitival verb phrase, 
the Eleme progressive constructions require both a locative verb ( $d o$ 'be located/exist' or $t \tilde{\jmath}$ 'stay, live') and a comitative-like applicative $=r \tilde{u}$ as well as a nominalised verb phrase.

Eleme progressive constructions with the verb $t \tilde{\partial}$ 'stay, live' as the lexical head have the same morphosyntactic properties as those constructions featuring $d o$, except they may only be understood to refer to past time. For example, the first construction in (18a) is characterised by the presence of $d o$ as the inflected stem. On the other hand (18b) is an example of a past progressive construction. It is structurally analogous to (18a) and differs only in that the inflected stem is $t \tilde{\jmath}$ 'stay, live', rather than the generic locative verb.
a. è-do-ri=rú́
e-fò-e
ǹsógũ
3-be.located-3PL=APPL DEP-plant-DEP fluted.pumpkin

'They are/were in the process of planting pumpkin.'

$\begin{array}{lll}\text { b. } \grave{\varepsilon} \text {-t̃̃-ri=rú } & \text { e-fò-e } & \text { ǹsógũ } \\ \text { 3-stay-3PL=APPL } & \text { DEP-plant-DEP } & \text { fluted.pumpkin }\end{array}$

'They *are/were in the process of planting pumpkin.'

The development of this temporal distinction in Eleme has significant consequences for the TAM system of the language. In particular, it shows early signs of developing a grammaticalised system of tense within progressive constructions, although not elsewhere in the system; in Eleme, temporal deixis is a secondary characteristic of grammaticalised aspect or modality and not manifested by distinct tense marking. Frequently, time reference is only discernable from the discourse context. This is certainly true of constructions containing the locative verb $d o$, which may be interpreted with either present or past time reference. The distinction between these two constructions is tentatively 
described as semi-grammaticalised because, while the construction in (18b) may only be used to refer to the past, the use of $d o$ for past time reference is nonetheless permissible in progressive constructions (19), demonstrating that the general locative verb has not yet entered into a mutually exclusive tense distinction.

$$
\begin{array}{lllll}
\text { té-Pù-ri òsốõ } & \text { òsíla } & \mathbf{d o}=\mathbf{r u ́} & \text { e-kpèègbe } \\
\text { when-die-3PL yesterday } & \text { Osila } & \text { be.located=APPL } & \text { DEP-beat.drum }
\end{array}
$$

'When they died yesterday, Osila was beating a drum.'

A common phonological feature of the locative-progressive construction and those containing $=r \tilde{u}$ in general is elision between the encliticised locative verb and the following complement. While the examples provided above exhibit a prosodic boundary between the locative verb and dependent verb, this is not always the case, as illustrated by (20). In (20) the vowel of the locativeapplicative is deleted while the high tone remains, resulting in the phonological integration of the inflected stem and the dependent verb. This example directly contrasts the one in (17) where elision of the final vowel of the verb stem has not taken place.

$$
\begin{aligned}
& \text { ǹ-do=r-é-tere ìdzirá } \\
& \text { 1sG-be.located=APPL-DEP-cook fish } \\
& \text { 'I am in the process of cooking fish.' }
\end{aligned}
$$

This elision phenomenon is interesting for two main reasons. Firstly, because other phonological material is seemingly 'stacked' on a formative that has some properties associated with clitics (see section 3), and secondly because in the speech of some individuals a pause is possible between the dependent verb marker and the (dependent) verb root in progressive constructions: $\grave{n}-d o=r$ - $\boldsymbol{e}$ \# tere 
ǹdzirá. Where a pause is made, the phonological realisation of the construction and the underlying grammatical structure are mismatched.

\section{MORPHOSYNTACTIC PROPERTIES OF $=r \tilde{u}$}

In the examples so far encountered, the locative-applicative has appended directly

to the verb stem. However, one of the most interesting characteristics of the $=r \tilde{u}$ morpheme is that it exhibits properties not typically associated with verbal affixes, principally in terms of its degree of selectiveness; the locative-applicative has some properties that make it more clitic-like than affix-like. This is clearly one of the factors that make arriving at an adequate description of the formative difficult. In section 3.1 the variable position of $=r \tilde{u}$ will be discussed in relation to constructions containing the verb of transfer $n^{w} \mathcal{\varepsilon}$ 'put (something)', this is followed in section 3.2 by discussion of possible alternative analyses of $=r \tilde{u}$ and of why this formative appears to be atypical in nature regardless of the piece of terminology used to label it.

\subsection{The locative-applicative with a verb of transfer}

In addition to verbs of directed motion (where the subject of the verb is agentive in the process of moving him/herself), and verbs of static location (where there is no relevant movement encoded), the locative-applicative also occurs alongside verbs of transfer, where an agent moves a theme. This is exemplified by the transitive verb $n^{w} \varepsilon$ 'put (something)' in (21a). Importantly, when the locativeapplicative is present as in (21b) it is not adjacent to the verb stem, but rather follows the base object of the verb. 
a. òsáro $\mathrm{n}^{\mathrm{w}} \bar{\varepsilon}$ ǹna oso mòló
Osaro put meat in soup

'Osaro put meat into the soup.'

b. òsáro $\mathrm{n}^{\mathrm{w}} \grave{\varepsilon}$ ǹna=rú́ mòbaló

Osaro put meat=APPL soup

'Osaro added (finely chopped) meat to the soup.'

*‘Osaro added (chunks of) meat to the soup.'

In (21a), ǹna 'meat', a P argument, is identified as being put in a location introduced by the preposition oso 'in/into/at'. The meat does not become part of the liquid of the soup, but rather something that can be recognised as a separate entity in the soup. As such the meat is still individuated from the liquid. This construction has three participants, with one of them encoded obliquely in a prepositional phrase. This construction is also used for other substantial components added to soup such as ìdzirá 'fish'. If the applicative is used, as in (21b), the construction is only permissible if the pieces of meat were chopped so finely that they became part of the liquid. In such instances, the meat and soup are less separable than when chunks of meat are transfered into the soup. In (21b), ǹna 'meat' is the $\mathrm{T}$ argument and mibaló 'soup' is the $\mathrm{R}$ argument. Whether the locative-applicative or oblique strategy is used to encode the third participant depends on the degree of individuation of the meat from the soup in these examples. Compare the examples in (21) with those in (22), where the base object is ̀̀ló 'salt': 
a. òsáro $\mathrm{n}^{\mathrm{w}} \grave{\varepsilon}$ ǹló oso mòbaló

Osaro put salt in soup

'Osaro put (an unpalatable amount of) salt into the soup.'

*`Osaro put (a palatable amount of) salt into the soup.'

b. òsáro $\mathrm{n}^{\mathrm{w}} \grave{\varepsilon}$ ǹló=rú mòbaló

Osaro put salt=APPL soup

'Osaro added salt to the soup.'

In (22a) a substantial amount of salt has been put into the soup. Although it may be dissolved, it may still be conceived of as individuated - in this case as a dominant flavour. In contrast, in (22b) ǹló 'salt', the T argument, is added to the soup and may no longer be individuated from the rest of the liquid. The construction in (22b) is the preferred construction type with ìló 'salt', while (22a) is pragmatically marked. As with (21b), (22a) sounds odd unless a highly specific interpretation is made. Other ingredients treated in a similar way to salt are ìn 'oil' and m̀mú 'water'. In both sets of constructions, =rú is used when the substance in question (the Figure) cannot be easily individuated from the thing it is put into (the Ground). The semantic differences between each pair of clauses are reflected in a change in grammatical valence from a bivalent verb with an oblique phrase in (21a) and (22a), to a trivalent verb in (21b) and (22b). This is reflected in the translation of these sentences into English where put signals an oblique terminal endpoint location, whereas add signals inclusion of one entity in another larger entity or group of entities. The constructional preference for 'putting meat (into)' vs 'adding salt' to soup falls out form the real world differences between salt - which naturally dissolves into liquid - and chunks of meat - which do not. One possible interpretation of the function of $=r \tilde{u}$ in these examples is that it has a comitative function like with the static location verbs 
discussed in section 2.3. ${ }^{12}$ This seems like a highly appropriate analysis given the semantic contrast between the sets of clauses in (21) and (22).

In (23), the locative-applicative attaches after a possessor affix $-y o$ on èmáygi, and not to the verb stem. ${ }^{13}$ In contrast to the locative-applicative, other verbal morphology occurs on the verb stem in this example. The terminal end point, i.e. the soup, is not encoded directly in this example, as inanimate objects are not typically marked by pronominal affixes.

$$
\begin{array}{lll}
\text { w-ò-kpãrã } & \mathrm{n}^{\mathrm{w}} \grave{\varepsilon} \text {-ra } & \text { èmángi-yo=rṹ } \\
\text { CONJ-2-want } & \text { put-also } & \text { maggi-2SG.POSS=APPL }
\end{array}
$$

'And (if) you want, add your Maggi to it too.'

Particularly clear examples of the less selective properties of the locativeapplicative can be seen in (24), where $=r \tilde{u}$ attaches at the right edge of a relative

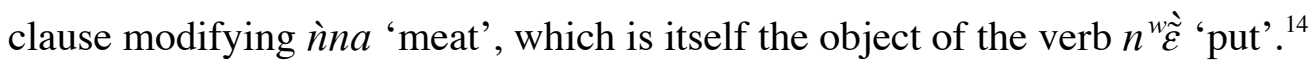

$$
\begin{aligned}
& \text { òsáro } \mathrm{n}^{\mathrm{w}} \mathrm{\varepsilon} \text { ǹna } \mathrm{r} \text {-a-bere biní=rú̃ maló } \\
& \text { Osaro put meat REL-3.AP-ANT be.cooked.through=APPL soup } \\
& \text { 'Osaro added (finely chopped) cooked meat to the soup.' }
\end{aligned}
$$

What is important about these examples is that in contrast to those containing ?à 'leave' and $g^{w} \tilde{\tilde{a}}$ 'reach' discussed in the previous section, =rú is not adjacent to the verb stem. It is clear from this contrast that $=r \tilde{u}$ is not a verbal affix since it does not only attach to verbs. Likewise it is not a nominal affix since it does not always attach to nouns. Variation in the position of the locative-applicative provides some support for analysing it as a clitic rather than an affix. ${ }^{15}$

In phonological terms, the locative-applicative shows signs of low phonological independence: a pause is not possible between $=r \tilde{u}$ and the host to 
which it attaches and its vocalic nucleus is frequently deleted in connected speech. Note that no verbal morphology ever appends to a verb stem after the locativeapplicative. ${ }^{16}$ Regardless of the position of the locative-applicative in relation to the verb stem and its arguments, the examples in (21) illustrate that the locativeapplicative allows for a new core argument to be expressed in the clause.

Evidence has been presented indicating that the host of $=r \tilde{u}$ can vary in lexical category, as indicated by the examples provided in (21), where it attaches to a noun, and (24), where it attaches to a verb. These data demonstrate that $=r \tilde{u}$ is an atypical applicative in that it is not selective about the type of host it attaches to.

\subsection{Some possible alternative analyses of $=r \tilde{u}$}

Variation in the position of $=r \tilde{u}$ in the clause raises concerns about the grounds on which this atypical applicative can be distinguished from a preposition, or a serialised verb, especially given potential differences attested between the phonological and morphological hosts of clitics/phrasal affixes (Klavans 1985, and also Bickel \& Nichols 2007: 174-80 for a recent discussion of this issue) and the attested source morphology for applicatives cross-linguistically (see Peterson 2007: 123-33 for an overview). Previous description of the locative-applicative is restricted to some comments by Obele (1998: 121), who describes this formative as a suffix that functions as a preposition. It has been demonstrated above that

$=r \tilde{u}$ is not a suffix, and in the following exposition, its status as a preposition will be discussed.

As first indicated in section 2, Eleme has a number of prepositions with locative semantics. The most common prepositions, with their basic characterisation are given in Table 1. Eleme prepositions are characterised by a VCV or NCV structure, which suggests they may have had nominal origins (i.e. their form suggests they may exhibit fossilised/vestigial classification prefixes of Eleme nouns (Bond \& Anderson 2006: 16)). 


\section{TABLE 1 HERE}

If we were to classify $=r \tilde{u}$ as a preposition, it would be non-canonical in relation to other prepositions in the language. From a phonological perspective, it does not have the syllable structure of a regular preposition and begins with $[\mathrm{I}]$, which is only found intervocalically in roots or in initial position with (typically dependent) grammatical formatives. Furthermore, while the prepositions in Table 1. are well defined in terms of the type of spatial relations they encode, the semantic role encode by $=r \tilde{u}$ is entirely dependent on the verb stem with which it is associated, and not by any semantic content of $=r \tilde{u}$ itself. This makes it more reminiscent of a component in a complex predicate, especially given the fact that it invokes both comitative and disassociative readings depending on the verb to which it attaches (not the type of object that it introduces).

The additional argument introduced by $=r \tilde{u}$ can optionally occur with a preposition, as in (25), which again can be compared directly with (22b) where no preposition is present. In (25), the preposition intervenes between $=r \tilde{u}$ and the argument it introduces:

$$
\begin{array}{llll}
\text { òsáro } \mathrm{n}^{\mathrm{w}} \bar{\varepsilon} & \text { ǹló=rú̃ } & \text { oso } & \text { m̀baló } \\
\text { Osaro put } & \text { salt=APPL in } & \text { soup }
\end{array}
$$

'Osaro added salt to the soup.'

In terms of a wider typology of three participant events, constructions of the type given in (25) are examples of what Margetts \& Austin (2007: 402) call the oblique applicative strategy. In three participant events of this kind one participant is encoded as an oblique marked NP (in (25) this is ṁbaló 'soup' which is marked as oblique by the preposition oso 'in/into/at'), which is also 'licensed' by an applicative-like morphological marker on the verb (in this case the locative- 
applicative $=r \tilde{u})$. Note that when the $\mathrm{T}$ argument of a trivalent clause is clefted in Eleme, the resulting construction is impermissible with the preposition oso, as (26a) indicates. This example directly contrasts (26b). However, it is possible to cleft the $\mathrm{R}$ argument in this way, as illustrated by (27).

a. *ǹló be r-òsáro $\mathrm{n}^{\mathrm{w}} \mathrm{\varepsilon}=\mathrm{ru}$ oso mòbaló salt COP REL-Osaro put=APPL in soup Intended: 'Salt is what Osaro added to the soup.'

b. ǹló be r-òsáro $\quad \mathrm{n}^{\mathrm{w}} \grave{\varepsilon}=\mathbf{r u ́}$ mìbaló salt COP REL-Osaro put=APPL soup 'Salt is what Osaro added to the soup.'

(27) mìbaló be $\mathrm{r} \varepsilon$ ke òsáro $\mathrm{n}^{\mathrm{w}} \mathrm{\varepsilon}$ ǹló=rṹ $\quad$ oso soup COP REL PRTCL Osaro put salt=APPL in 'Soup is what Osaro added salt into.'

It is yet to be explained why (26a) is ungrammatical, while (25), (26b) and (27) are permissible, although it could be related to differences in the strategies used to cleft $\mathrm{T}$ and $\mathrm{R}$ arguments or the information-structural properties that $\mathrm{T}$ and $\mathrm{R}$ have in these applicative constructions.

While $=r \tilde{u}$ can be followed by a PP, as in (25), the reverse order is unattested and there is no evidence to suggest that any of the more regular prepositions can be stacked. Also, none of the 'true' prepositions can take dependent verb stems as a complement.

While the Eleme prepositions encode locative oblique functions, other functions that languages sometimes encode obliquely are introduced as core arguments through the use of the applicatives -se (benefactive) and - $m a$ 
(instrumental). Given that there are other applicatives in the language that introduce circumstantial roles as arguments, it is not strange to argue that $=r \tilde{u}$ is a locative-applicative. While $=r \tilde{u}$ is atypical in its morphosyntactic behaviour, it can be shown to either increase the valence of a verb, and/or introduce a complement that is semantically atypical for that verb.

While the current analysis differs from that of Obele, the examples he provides likewise indicate that the category of the host of =rí may vary, and further illustrate that variation in the position of $=r \tilde{u}$ occurs across speakers within constructions which have the same meaning. For example, Obele (1998: 262) provides two contrasting positions for the locative-applicative within the same predicate meaning 'love'. The compositional semantics of this construction are not transparent and this combination of elements appears to be fairly lexicalised. In (28a) the locative-applicative is attached to Osila, while in (28b) it is attached to the verb stem $m \grave{\partial}$ 'see'. ${ }^{17}$ While the relative order of the objects differ in each example, the relative order of $=r \tilde{u}$ and $\grave{a} d \tilde{\varepsilon}$ remains constant, suggesting a close structural relationship between these two elements, at least historically.

$\begin{array}{lc}\text { (28)a. mo osila=rũ ad } \tilde{\varepsilon} & \text { b. } \mathbf{m o =}=\mathbf{r} \text { ad } \tilde{\varepsilon} \text { osila } \\ \text { see Osila=APPL eye } & \text { see=APPL eye Osila } \\ \text { 'love Osila.' } & \text { 'love Osila.' } \\ \text { CONSERVATIVE } & \text { CONTEMPORARY }\end{array}$

(Obele 1998: 262)

Obele (1998: 262) attributes the differences in the position of the locativeapplicative to differences in the speech of 'adult' and 'newbreed' Eleme speakers. This latter group of speakers are said by Obele (1998: 259-60) to comprise 'newbreed indigenes of Eleme who were brought up outside Eleme' and 'stranger 
elements who are living in Eleme, and are injecting some of the structural patterns of their mother-tongues into the structure of the Eleme language.' While it is difficult to say with any certainty to what extent the so-called 'newbreed' constructions are influenced by the structure of other languages in contact with Eleme, what is important here is the position of the applicative morpheme in the latter construction. Based on Obele's sociolinguistic observations, it is likely that the 'adult' construction in (28a) is more conservative than the 'newbreed' construction in (28b). In turn, this suggests that (28a) is the syntactic precursor of the 'newbreed' construction in (28b). All of the examples containing the predicate meaning 'love' in the present corpus of Eleme conform to the less conservative structure, where the locative-applicative is attached directly to the verb stem and not to a following argument, as in (29):

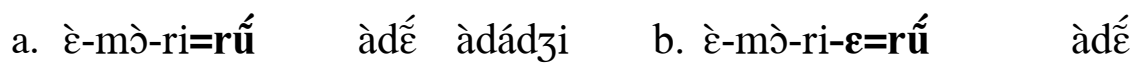

$$
\begin{aligned}
& \text { 3-see-3PL=APPL eye Adaji 3-see-3PL-3SG=APPL eye } \\
& \text { 'They loved Adaji.' 'They loved her.' }
\end{aligned}
$$

A further possibility concerning the origin of the locative-applicative $=r \tilde{u}$ is that it was originally a verb and that constructions containing $=r \tilde{u}$ are (at least historically) serial-verb constructions (SVC). There are a number of differences between $=r \tilde{u}$ and verbal forms that make this an unappealing analysis. In addition to the phonological characteristics of free formatives discussed above, =rí does not exhibit the agreement properties that genuine SVCs have, nor does it have the distributional properties of a genuine verb. The best examples to support this case have second-person plural subjects since in such instances each verb in the SVC is marked with an agreement affix indicating the plurality of the subject. Without the agreement suffix(es), the reading of (30) would be that it has a singular subject. 
ò-sí-i fó-i ǹdza

2-go-2PL plant-2PL food

'You (PL) went to plant food.'

Given this property of SVCs, one might expect the same to be true of constructions containing $=r \tilde{u}$ that have second-person plural subjects. However, this is not the case as illustrated in (31), where the head of the predicate do 'be located/exist' and the dependent verb form gbò̀ both bear agreement marking, but the locative-applicative does not.

$$
\text { ò-do-i=rṹ e-gbò̀-i è̀t } \quad \text { ṹ }
$$

2-be.located-2PL=APPL DEP-stitch-2PL clothes

'You (PL) are stitching clothes.'

Furthermore, following the criteria I use to distinguish SVCs from auxiliary verb constructions (AVCs), each component verb (i.e. each serialised verb) in a SVC must be able to stand alone as the head of a predicate. This is not a property shared by $=r \tilde{u}$ which never occurs as the head of a predicate. Although there is no convincing synchronic evidence for describing $=r \tilde{u}$ as a serialised verb, this does not rule of the possibility that it historically derives from such a construction.

The data provided in this section demonstrate that whatever analysis is chosen as the most appropriate for $=r \tilde{u}$ it will be characterised as an atypical member of that class of elements. However, given the valence-changing properties of this formative, and its close semantic relationship to the verb with which it is associated, analysing $=r \tilde{u}$ as a non-canonical locative-applicative affords the most robust description of this formative. 


\section{SUMMARY}

Applicative morphology is apparent in a range of grammatical constructions in Eleme. Discussion here has centred on the use of the locative-applicative $=r \tilde{u}$, a previously under-described formative.

The locative-applicative is employed in one of two functions: (i) to indicate an increase in the transitivity of a clause and (typically) to introduce an otherwise oblique function as a core argument of the clause, or (ii) to indicate the presence of an atypical verbal complement. The role of the core argument or the type of complement introduced by $=r \tilde{u}$ is determined by the semantic characteristics of the verbal predicate of which it is part. It is usually found in constructions containing a verb stem that expresses location, directed motion or transfer. With location verbs such as $d o$ 'be located/exist' and $t \tilde{\partial}$ 'stay, live' $=r \tilde{u}$ is used in a comitative function or to introduce an event nominal. With directed motion verbs such as $P \grave{a}$ 'leave' or $g^{w} \tilde{\tilde{a}}$ 'reach' =rú is used to indicate that an animate participant has the semantic function of locative complement, or to introduce an event nominal. In such cases the use of the applicative has very different interpretations depending on the head with which it is associated and may have comitative or disassociative readings. With transitive transfer verbs such as 'put' the applicative allows a thematically peripheral adjunct to be encoded as a core argument. These data demonstrate that the locative-applicative is selected on the basis of verbal semantics and argument structure, with the exact semantics of the construction dependent on the verb and the semantic function of its complement.

I have shown here that the locative-applicative is unlike a typical verbal affix since it demonstrates morphosyntactic properties commonly associated with clitics, yet the locative-applicative has derivational characteristics, even though its clitic-like properties make it unlike prototypical derivational morphemes. While an atypical applicative, it has also been demonstrated that $=r \tilde{u}$ exhibits different 
behaviour from genuine adpositions and component verbs in serial-verb constructions in the language.

The locative-applicative functions as an obligatory component of the Eleme progressive construction. In such constructions, the locative-applicative morpheme introduces a nominalised event as an obligatory complement of either do 'be located/exist' or $t \tilde{\partial}$ 'stay, live'. Event nominals encoded morphologically as dependent verb stems behave in a similar way to core functions rather than unmarked locative complements, even though they only ever occur in post-verbal position and do not have the same morphosyntactic characteristics of object arguments. While similar examples involving a comitative are proposed to exist in other Niger-Congo languages, Eleme is apparently unique within these languages in that the element with a comitative function in progressive constructions is enclitic to a verb of location.

Department of Linguistics

School of Oriental and African Studies

Thornhaugh Street

Russell Square

London WC1H OXG

United Kingdom

Email:oliver.bond@soas.ac.uk 


\section{REFERENCES}

ANDERSon, StePhen R., 2005. Aspects of the Theory of Clitics, Oxford: Oxford University Press.

ANDREWS, AVERY D., 2007. 'The major functions of the noun phrase', in Timothy Shopen (ed.), Language Typology and Syntactic Description, vol. 1, Clause Structure, 2nd edn., Cambridge: Cambridge University Press, 132-223.

Bickel, Balthasar, \& Nichols, Johanna, 2007. 'Inflectional morphology', in Timothy Shopen (ed.), Language Typology and Syntactic Description, vol. 3, Grammatical Categories and the Lexicon, 2nd edn., Cambridge: Cambridge University Press, 169-240.

BOND, OlIVER, 2005. 'The applicative marker in Eleme locative progressive constructions', paper presented at LAGB 2005, Fitzwilliam College, Cambridge.

BOND, Oliver, 2006a. Aspects of Eleme Verbal Morphosyntax, Ph.D. dissertation, University of Manchester.

BOND, OlIVER, 2006b. 'A broader perspective on point of view: logophoricity in Ogonoid languages', in John Mugane, John P. Hutchinson \& Dee A. Worman (eds.), Selected Proceedings of the 35th Annual Conference on African Linguistics: African Languages and Linguistics in Broad Perspectives, Somerville, MA: Cascadilla Proceedings Project, 234-244.

BOND, OLIVER, forthcoming. 'Intra-paradigmatic variation in Eleme verbal agreement'. Submitted to Lingua.

Bond, Oliver \& ANDERson, Gregory D. S., 2006. 'Divergent structure in Ogonoid languages' in Rebecca T. Cover \& Yuni Kim (eds.), Proceedings of the 31st Annual Meeting of the Berkeley Linguistics Society, Berkeley, CA: Berkeley Linguistics Society, 13-24.

BRosNaHAN, L. F., 1964. 'Outlines of the phonology of the Gokana dialect of Ogoni', Journal of West African Languages 1, 43-48.

BRosnaHAN, L. F., 1967. 'A word list of the Gokana dialect of Ogoni', Journal 
of West African Languages 4, 43-52.

Bybee, Joan L., Perkins, Revere, \& Pagliuca, William, 1994. The Evolution of Grammar: Tense, Aspect and Modality in the Languages of the World, Chicago: University of Chicago Press.

Comrie, Bernard, 1976. Aspect, Cambridge: Cambridge University Press.

Comrie, Bernard, 1978. 'Ergativity', in Winfred Lehmann (ed.), Syntactic Typology, Austin: University of Texas Press, 329-394.

Croft, William, 2003. Typology and Universals, 2nd edn., Cambridge: Cambridge University Press.

DAHL, ÖSTEN, 1985. Tense and Aspect Systems, Oxford: Blackwell. DimmendAAL, GERRIT J., 2003. 'Locatives as core constituents', in Erin Shay, (ed.), Motion, Direction and Location in Languages, Amsterdam: John Benjamins, 91-109.

DowTY, DAVID, 1991. 'Thematic proto-roles and argument selection', Language 67, 547-619.

FraWLEY, WiLliam, 1992. Linguistic Semantics. Hillsdale, NJ: Lawrence Erlbaum Associates.

HARFORD, CAROLYN, 1993, 'The applicative in Chishona and lexical mapping theory'. in Sam A. Mchombo (ed.), Theoretical Aspects of Bantu Grammar, Stanford, CA: CSLI, 93-111.

Heine, Bernd, Claudi, Ulrike, \& HÜnNEMEyer, Friederike, 1991. 'From cognition to grammar: evidence from African languages', in Elizabeth Closs Traugott, \& Bernd Heine (eds.), Approaches to Grammaticalization, vol 1, Amsterdam: John Benjamins, 149-188.

Heine, Bernd, \& KuteVA, TANiA, 2002. World Lexicon of Grammaticalization, Cambridge: Cambridge University Press.

HopPer, PAUl J., \& THOMPSON, SANDRA A., 1980. 'Transitivity in grammar and discourse', Language 56, 251-299.

HYMAN, LARRY M., 1982a. 'The representation of nasality in Gokana', in Harry van der Hulst \& Norval Smith (eds.), The Structure of Phonological Representations, part 1, Dordrecht: Foris, 111-130. 
HyMAn, LARRY M., 1982b. The representation of length in Gokana, in Daniel P. Flickinger, Marlys Macken, \& Nancy Wiegland, (eds.), Proceedings of the First West Coast Conference on Formal Linguistics, Stanford, CA:

Stanford University, 198-206.

Hyman, LARRY M., 1983. 'Are there syllables in Gokana?', in Jonathan Kaye, H. Koopman, D. Sportiche \& A. Dugas (eds.), Current Approaches to African Linguistics 2, Dordrecht: Foris, 172-179.

HyMAn, LARRY, \& COMRIE, BERNARD, 1981. 'Logophoric reference in Gokana', Journal of African Languages and Linguistics 3, 19-37.

IKORO, SuANu, 1994a. 'Numeral classifiers in Kana', Journal of African Languages and Linguistics 15, 7-28.

IKORO, SUANU, 1994b. 'The raised tone in Kana' in Thomas, Bearth, Wilhelm J. G. Möhlig, Beat Sottas, \& Edgar Sutter (eds.), Perspektiven africanistischer Forschung, Beiträge zur Linguistik, Ethnologie, Geschichte, Philosophie und Literatur, X. Afrikanistentag, Cologne: Rüdiger Köppe, 201-216.

IKORO, SUANU, 1995. 'A new approach to tone in associative constructions: insights from Kana', in E. Nolue Emenanjo, \& Ozo-mekuri Ndimele (eds.), Issues in African Languages and Lingusitics: Essays in Honour of Kay Williamson, Aba: National Institute for Nigerian Languages, 51-63. IKoro, SuANu, 1996. The Kana Language, Leiden: CNWS Publications. KLAVANS, JUDiTH L., 1985. 'The independence of syntax and phonology in cliticization', Language 61, 95-120.

LAdEFOGED, Peter, 1995. 'Voiceless approximants in Tee', in E. Nolue Emenanjo \& Ozo-mekuri Ndimele (eds.), Issues in African Languages and Lingusitics: Essays in Honour of Kay Williamson, Aba: National Institute for Nigerian Languages, 45-50

Mabugu, Patricia, 2002. Polysemy and the Applicative Construction in Chishona, Ph.D. dissertation, University of Edinburgh.

MABUgu, PATRICIA, 2004. 'A unitary description of the interpretations of ChiShona applicatives', in Chege, Githiora, Heather Littlefield, \& Victor 
Manfredi (eds.), Kinÿra Njra!: Step firmly on the path, Trenton, NJ: Africa World Press, 171-184.

Margetts, Anna \& Austin, Peter K., 2007. 'Three-participant events in the languages of the world: towards a cross-linguistic typology', Linguistics 45, 393-451.

MARTEN, Lutz, 2002. At the Syntax-Pragmatics Interface, Oxford: Oxford University Press.

Marten, Lutz, 2003. 'The dynamics of Bantu applied verbs: an analysis at the syntax-pragmatics interface', in Kézié K. Lébikaza, (ed.), Actes du $3 e$ Congrès Mondial de Linguistique Africaine Lomé 2000, Köln: Köppe, 207221.

NwÍ-BÀRÌ, WILSON KPÀKPÀN, 2002. Tèè-English dictionary: Tabtàb Tèè turé bu bèkéé, Port Harcourt: Onyoma Research Publications.

Obele, Nwolu-, Chief Dada, 1998. Foundation studies in Eleme, Port Harcourt: Outreach Publications.

Peterson, DAVID, A., 2007. Applicative Constructions. Oxford: Oxford University Press.

RAPOLD, Christian, 1997. The Applicative Construction in Lingala, unpublished MA thesis (scriptie), Rijksuniversiteit Leiden.

ROBERTS, IAN, 1985. 'Serial verbs and government binding theory', Studies in African Linguistics Supplement 9, 262-268.

SCHADEBERG, THILO C., 1990. A Sketch of Umbundu. Köln: Rüdiger Köppe Verlag.

Siewierksa, AnNa, 2004. Person, Cambridge: Cambridge University Press.

VAlEnTE, José Francisco. 1964. Gramática Umbundu, a língua do centro de Angola, Lisbon: Publisher unknown.

TALmy, LeONARD, 2000. Toward a Cognitive Semantics, vol 1: Concept Structuring Systems, Cambridge, MA: MIT Press.

TALMY, LEONARD, 2007. 'Lexical typologies', in Timothy Shopen (ed.), Language Typology and Syntactic Description, vol. 3: Grammatical 
Categories and the Lexicon, 2nd edn., Cambridge: Cambridge University Press, 66-168.

Timberlake, Alan, 2007. 'Aspect, tense, mood', in Timothy Shopen (ed.), Language Typology and Syntactic Description, vol. 3: Grammatical Categories and the Lexicon, 2nd edn., Cambridge: Cambridge University Press, 280-333.

WAGNER, DonNA, 1985. 'Objects in Gokana', Studies in African Linguistics Supplement 9, 304-308.

Williamson, KAY, 1973. Reading and Writing Eleme, Port Harcourt: River Readers Project.

WilliamsOn, KAY, 1985. 'How to become a Kwa language', in Adam Makkai \& Alan K. Melby (eds.), Linguistics and Philosophy: Essays in Honor of Rulon S. Wells, Amsterdam: John Benjamins, 428-443.

ZWICKY, ARNOLD M., 1977. On Clitics, Bloomington, IN: Indiana University Linguistics Club.

${ }^{1}$ I gratefully acknowledge the role of the AHRC (doctoral award) and the ESRC (postdoctoral award No. PTA-026-27-0883) in providing the financial support necessary to carry out this research. This work could not have been attempted without the support of my Eleme consultants (too numerous to name individually here), and I am especially grateful to Enu-Obari Ekaka-a for his valuable time and knowledge. I would also like to thank Leora Bar-el, Kersti Börjars, Grev Corbett, Bethwyn Evans, Martina Faller, Kristine Hildebrandt, Anthony Jukes, Louise Mycock, John Payne, Malin Petzell, Jeanette Sakel and four anonymous reviewers for providing comments on earlier drafts of this paper. The conclusions presented here also benefited from the suggestions of the participants at the Annual Meeting of the LAGB, 2005 in Cambridge, where the data included in this paper were first presented (Bond 2005).

${ }^{2}$ All of the data in this paper is from Eleme and was collected by the author between October 2001 and March 2006. Earlier works on Eleme comprise Wolff 
(1964), Williamson (1973, 1985), Obele (1998), Bond (2006a, b), Bond \& Anderson (2006). Most of the examples provided here were initially taken from texts. It is only through careful analysis of the distribution of $=r \tilde{u}$ throughout natural speech data that the observations and claims made here have been possible.

${ }^{3}$ This is most likely due in part to definiteness or referentiality, but given that neither of these properties is indicated morphologically on NPs, this awaits a more in-depth discourse-based analysis.

${ }^{4}$ See section 3.2. for examples and discussion of the properties of prepositions in Eleme.

${ }^{5}$ Abbreviations used in this paper are: 1 - first person, 2 - second person, 3 third person, A - agent-like argument of canonical transitive verb, ANT - anterior, AP - anterior-perfective, APPL - applicative, BEN - benefactive, CONJ conjunction, CONT - continuous, COP - copula, DEP - dependent, EXST - existential form, G - ditransitive goal, HAB - habitual, INS - instrumental, LOC - locative, NP - noun phrase, $\mathrm{O}$ - object, $\mathrm{P}$ - patient-like argument of canonical transitive verb, PL - plural, POSS - possessive, PP - prepositional phrase, PRTCL - particle, R ditransitive recipient, REL - relative, T - ditransitive theme, TAM tense/aspect/mood, TRANS - transitive, S - single argument of canonical intransitive verb, SG - singular, SPF - specific, V - verb, * - ungrammatical construction. The $=$ sign is used to indicate clitic boundaries.

${ }^{6}$ The uppercase letters found on these forms indicates that they are semantic relations, not grammatical ones. See Talmy (2001: 315-6) for a list of the defining (and associated) characteristics of Figure and Ground.

${ }^{7}$ Locations, broadly construed, may have a variety of semantic roles; see Andrews (2007) for some examples.

${ }^{8} \mathrm{I}$ am not aware of any alternative term in the general literature for this use of an applicative, or if this term has a precedent elsewhere.

${ }^{9}$ Eleme has a particularly complex system of participant reference, discussed at length in Bond (2006a) and Bond (forthcoming). Some of this complexity is 
represented in the examples below. First-person plural subjects are always indexed with a prefix and first-person singular typically so. Third-person singular forms with an NP or independent pronoun as subject are zero marked while comparable constructions with third-person plural subjects require an agreement suffix -ri.

${ }^{10}$ Periphrastic progressives have not been reported in the existing descriptions of the other Ogonoid languages, nor is there any evidence that cognates of $=r \tilde{u}$ are found in them either. Sources for this conclusion comprise Brosnahan (1964, 1967), Hyman \& Comrie (1981), Hyman (1982a, b, 1983), Wagner (1984), Roberts (1985), Williamson (1985), Ikoro (1994a, b, 1995, 1996). Ladefoged (1995), Nwí Bàrì (2002).

${ }^{11}$ I am grateful to an anonymous reviewer for pointing this out to me.

${ }^{12} \mathrm{I}$ am grateful to an anonymous reviewer for pointing this out to me.

${ }^{13}$ Maggi is a brand of stock cube/food flavouring commonly used in West African cooking. Like salt, Maggi dissolves into the liquid to which it is added.

${ }^{14}$ Note that while $=r \tilde{u}$ may occur on verbal stems and non-derived NPs, there is no evidence to suggest that it occurs on dependent verb stems.

${ }^{15}$ The term clitic has a wide range of uses in the literature and is the subject of much debate; for instance, see Zwicky (1977), Klavans (1985), S. Anderson (2005), Bickel \& Nichols (2007). This distinction will not be discussed further here although it is noted that this variation in distribution is an interesting facet of the behaviour of $=r \tilde{u}$.

${ }^{16}$ Although the locative-applicative always bears a high tone, distinctive tone is a common property of phonologically bound formatives and grammatical words in Eleme. This indicates that the presence of distinctive tone is not a suitable criterion for distinguishing phonologically free units from phonologically bound ones in Eleme. The stress system of Eleme remains to be studied and therefore additional evidence from this domain will not be discussed here. No lexical item has $[\mathrm{I}]$ in word-initial position in Eleme. In contrast, initial $[\mathrm{I}]$ is common for 
formatives that are described in this study as affixes, indicating phonological similarity between $=r \tilde{u}$ and other bound forms in the language.

${ }^{17}$ Note that the following examples are unmarked for tone, which is how they were presented in the source material. As a consequence, it is difficult to tell if they are provided as examples of imperatives or sentence fragments. 